\title{
Educação em direitos humanos em tempos de crise
}

\author{
Human rights education in times of crisis
}

\author{
D Linda Carter Souza da Silva \\ Mestrado em Educação \\ Secretaria de Educação do Estado do Rio Grande do Norte - SEEC. \\ Mossoró, RN - Brasil. \\ lindacarterlinda@hotmail.com \\ Luiz Gomes da Silva Filho \\ Doutorado em Educação \\ Universidade Federal Rural do Semi-Árido - UFERSA. \\ Mossoró, RN - Brasil. \\ luiz.gomes@ufersa.edu.br
}

Resumo: O estudo tem por objetivo apresentar reflexões acerca da Educação em Direitos Humanos considerando um contexto de crise permanente do Estado. A metodologia se assenta em uma abordagem qualitativa sendo uma pesquisa exploratória que tem por método o levantamento e análise de fontes bibliográficas. Os resultados alcançados evidenciam que tal crise dificulta o processo de tomada de decisões estendendo as dificuldades a setores como assistência social, moradia, saúde e educação. É nesse cenário, que se considera de fundamental importância educar para os direitos humanos. Essa proposta de educação, afirma a escola enquanto lugar de acesso, garantia e conhecimento sobre os direitos humanos, perspectivando assim, a luta por justiça social e dignidade humana.

Palavras - Chave: Crise. Educação. Direitos humanos.

Abstract: The study aims to present reflections about Human Rights Education considering a context of permanent crisis of the State. The methodology is based on a qualitative approach and is an exploratory research that has as a method the survey and analysis of bibliographic sources. The results obtained show that this crisis hinders the decision-making process by extending difficulties to sectors such as social assistance, housing, health and education. It is in this scenario that it is considered fundamental importance to educate for human rights. This proposal of education, affirms the school as a place of access, guarantee and knowledge about human rights, thus aiming at the struggle for Social Justice and Human Dignity.

Keywords: Crisis. Education. Human rights. 


\section{Considerações iniciais}

A Sociedade atual revela vieses de desumanização e aprofundamento da negação do outro. A padronização imposta pressupõe punição, ausência de direitos básicos à manutenção da vida e estigmatização. Somos convidados diariamente a assistir a ventilação do ódio propagado como instrumento de manipulação midiática, a utilização das redes sociais como aparelho de vinculação de notícias falsas e a reprodução de discursos preconceituosos por representantes e instituições que deveriam resguardar o Estado de Direito. Isentos de fundamentação filosófica, social, cultural e legal, esses discursos expõem a necessidade urgente de reconstrução da sociedade enquanto coletividade em convivência.

Desse modo, nos perguntamos qual o papel da escola diante desse cenário enquanto instituição voltada à formação integral do sujeito. Considerando que, uma das funções primordiais dessa instituição reside na necessidade de desnaturalizar, combater e conscientizar seus estudantes, sobretudo no que diz respeito as diferentes formas de violação de direitos. Quando visitamos o marco legal, encontramos na Base Nacional Comum Curricular (2018, p. 61) que o compromisso da escola deve ser:

[...] de propiciar uma formação integral, balizada pelos direitos humanos e princípios democráticos, é preciso considerar a necessidade de desnaturalizar qualquer forma de violência nas sociedades contemporâneas, incluindo a violência simbólica de grupos sociais que impõem normas, valores e conhecimentos tidos como universais e que não estabelecem diálogo entre as diferentes culturas presentes na comunidade e na escola.

Sob tal égide, a necessidade de um percurso que compreenda a educação como transformadora de realidades vulneráveis aponta para um modelo que dialoga com a Educação em Direitos Humanos. Buscando assim, transformação que evidencie respeito, tolerância e conscientização. Comungamos com o Programa Mundial para a Educação em Direitos Humanos (2012) ao referenciar essa proposta de educação com as seguintes características:

[...] uma educação integral em direitos humanos não somente proporciona conhecimentos sobre os direitos humanos e os mecanismos para protegê-los, mas que, além disso, transmite as aptidões necessárias para promover, defender e aplicar os direitos humanos na vida cotidiana. A educação em direitos humanos promove as atitudes e comportamento necessários para que os direitos humanos de todos os membros da sociedade sejam respeitados.

Em tempos de insensatez, a escola se materializa enquanto espaço de reflexões sobre ser/estar no mundo. Na escola, a Educação em Direitos Humanos pode solidificar-se enquanto proposta curricular de enfrentamento e resistência a uma retórica esvaziada de conhecimento científico e principalmente de solidariedade. Podendo colocar-se como afirmação e efetivação dos direitos humanos. 
Por entendermos a indagação como ponto de partida para o aprofundamento do tema, partimos da seguinte pergunta: Como propor uma educação em/para os direitos humanos em tempos de crise?

A priori, refletir o cerne de uma crise forjada no seio de uma sociedade excludente é fundamental a partir da compreensão do termo. Conforme o Dicionário Michaelis online (2019), a Crise sob uma perspectiva sociológica diz respeito a: "Conjuntura desfavorável; situação anormal e grave; conflito, tensão, transtorno." Conjecturar as visões históricas, políticas e sociais que emergem dos mais diversos conflitos, requer sobretudo, aprofundamento sobre um Estado permanente de crise. Diante disso, nos propomos a pensar a crise sob o prisma da instituição escolar. A negação da escola enquanto negação do direito humano se assenta na visão societária enraizada na classe dominante.

O estudo se justifica pela relevância do tema na atualidade mediante os frequentes casos de negligência na concretização dos direitos humanos, estando a escola entre esses espaços de negação. O interesse pela temática advém da formação dos pesquisadores junto a Especialização em Educação em Direitos Humanos, promovida pela Universidade Federal do Rio Grande do Norte (UFRN) (2014-2015), em parceria com a extinta Secretaria de Educação Continuada, Alfabetização, Diversidade e Inclusão (SECADI/MEC). O que permitiu conhecer, discutir e pensar uma educação em que a garantia dos direitos humanos seja pedra basilar para uma educação libertadora.

$\mathrm{O}$ aporte metodológico da pesquisa em questão tem por base a abordagem qualitativa em educação (BOGDAN \& BIKLEN, 1994), se caracterizando como uma Pesquisa Exploratória. Segundo Gil (1999) esse tipo de pesquisa parte de uma realidade social ampliando a discussão sobre uma visão geral de determinado fato. Podemos indicar como método de pesquisa exploratória o levantamento e análise de fontes bibliográficas.

As fontes bibliográficas mais conhecidas são os livros de leitura corrente. No entanto,
existem muitas outras fontes de interesse para realização de pesquisas, ta.is como: obras
de referência, teses e dissertações, periódicos científicos, anais de encontros científicos e
periódicos de indexação e resumo (GIL, 2008, p. 61).

Sob este prisma, buscamos evidenciar em um primeiro momento a crise atual enquanto ferramenta de reflexão histórica, além de reprodutora maciça de negação de direitos humanos, mais especificamente, no contexto escolar. Também, pensar a escola como lugar de possibilidades para o enfrentamento da crise por meio da conscientização e transformação social, culminando em uma proposta com base na Educação em Direitos Humanos. 


\section{Crise ou estado de crise? questões contemporâneas}

A ideia de Crise enquanto estado de desfavorecimento econômico sustenta-se em um discurso de base capitalista que relaciona a produtividade, a eficácia e a eficiência à estabilidade financeira. Junto a esse ideário, consolidou-se grandes crises históricas que se assumiram ora como ruptura de modelos econômicos e sociedades, ora como manutenção do status quo. Conforme Touraine (2011, p. 14): “[...] não é a crise que engendra um novo tipo de sociedade, mas ela contribui para a destruição do velho modelo e pode igualmente impedir a formação de um novo tipo de sociedade ou favorecer a intervenção de atores autoritários num período de difícil transição".

Não podemos afirmar que o sinônimo de crise seja transformação em seu aspecto positivo, mas pensá-la sob a ótica das possibilidades nos remete a dualidade do avanço ou retrocesso que permeia a linha tênue de uma sociedade. Historicamente, as consideradas crises tiveram por ponto de partida a deterioração de uma estrutura vigente. A atuação ou ausência do Estado se apresenta como ponto crucial e determinante para a reorganização social, econômica, cultural e educacional de uma sociedade.

No início do século XX, a crise de 1929, considerada uma crise industrial desponta enquanto período de recessão, sob a qual, propõe-se a aplicação das teorias de Keynes. Encabeçada pela queda repentina da bolsa de valores de Nova York, tal crise tem por base o declínio da atividade industrial, enfraquecimento das atividades agrícolas, saturação do setor imobiliário e desorganização bancária (GAZIER, 2009).

Sendo os Estados Unidos uma grande potência econômica do período, a desestabilização do mercado provocado pela crise ascende um cenário de colapso influenciando diretamente por processos considerados estáveis como a superprodução e a especulação, como afirma Hobsbawm (1995, p. 84):

O que acontecia, como muitas vezes acontece nos booms de mercados livres, era que,
com os salários ficando para trás, os lucros cresceram desproporcionalmente, e os
prósperos obtiveram uma fatia maior do bolo nacional. Mas como a demanda da massa
não podia acompanhar a produtividade em rápido crescimento do sistema industrial nos
grandes dias de Henry Ford, o resultado foi superprodução e especulação. Isso, por sua
vez, provocou o colapso.

Ainda pensando a partir da perspectiva histórica, entre os anos de 1970-1980 os Estados Unidos protagonizam uma crise de crédito imobiliário, porém, apesar da falência de bancos, foi possível manter o mercado de capitais de pé como principal fonte de investimento. O mesmo não se evidencia na crise bancária do Japão (1980-1990) pois, o modelo econômico diferentemente dos Estados Unidos se apoiava em bancos e não no mercado de capitais. O mundo assistiu essas crises 
financeiras com apreensão, contudo, não vivenciou as consequências diretas dos contextos. Alain Touraine afirma que a crise atual foi precedida por várias outras crises menos massivas, mas que já anunciavam a fragilidade do sistema financeiro.

Em 1990, a crise dos "Savings e Loans," isto é, das caixas econômicas americanas, teve um papel fundamental na recessão de 1991-1992. Em 1995, a queda retumbante do Banco Barings, na Grã Bretanha, em seguida, em 1998, o esvaziamento de alguns fundos especulativos anunciaram as tormentas vindouras. Após a explosão da bolha informática em 2001, seguida pelo escândalo de Enron (31 de Outubro de 2001), pelo krach do fundo Amaranth, pela crise dos subprimes nos Estados Unidos a partir de 2007, tudo culminou numa crise generalizada. A falência do Lehaman Brothers, no dia 15 de Setembro de 2008, detonou a catástrofe (TOURAINE, 2011, p. 46).

Tal retomada histórica nos remete a efervescência dos sucessivos contextos de crise mundial, os quais, influenciaram de alguma maneira a organização da sociedade atual. Como pensar tais crises sem associá-las a estabilidade ou falta dela nos campos sociais e políticos?

Mais recentemente, o mundo vivenciou os desdobramentos da crise de 2008. Seu estopim se deu através do estouro da bolha imobiliária nos Estados Unidos ocasionado pela fuga de capitais do estagnado sistema econômico para o mercado hipotecário, ocasionando o início da hiperespeculação (GIL \& BARIZ̃̃O, 2012). Tendo, inclusive, a lógica capitalista como força motriz encabeçada pelo Estado, que, por sua vez, direciona as condições sociais, econômicas e ideológicas beneficiando setores específicos e estratégicos.

A crise tem por dever essencial potencializar a tomada de decisões. A revisão de setores específicos que engendram o movimento da sociedade é fundamental para estabelecer um caminho viável na promoção do bem estar-social. Sendo pressuposto de mudanças, a crise atual perpassa a ideia de Estado de Crise por apresentar-se como permanente no sentido de requerer um diagnóstico e, consequentemente, uma ação.

De acordo com Bauman \& Bordoni (2016, p. 28): “A crise do Estado se deve à presença desses dois elementos: incapacidade de tomar decisões concretas no âmbito econômico e, portanto, a incapacidade de prover serviços sociais adequados". O que retira apenas do âmbito econômico as consequências geradas, mas eleva a outros setores, como saúde, assistência social, moradia e educação. Sendo esse último o foco do nosso estudo. Portanto, na seção seguinte, traremos reflexões sobre a escola e a educação em direitos humanos como caminho possível no estado de crise sob o qual, estamos inscritos cotidianamente.

\section{A negação da escola: um discurso que aprofunda a crise educacional}

A crise do Estado é uma crise que invariavelmente se espraia por todas as suas agências e instituições. Desse modo, o setor público/Estatal vem sofrendo ataques das mais variadas 
naturezas e que carregam em seu cerne a negação do público em detrimento da ideologia do setor privado como sinônimo de eficaz, moderno e eficiente (BALL, 2011). Contudo, dentre os alvos em potencial, a educação pública, tanto na esfera básica quanto universitária, vem atravessando um dos momentos mais desafiadores de sua história moderna, que reside especialmente na narrativa que nega a escola enquanto espaço de construção de saberes e convivência social.

Mas quais os reais motivos que levam setores sociais a sustentarem uma narrativa de negação à escola? Por que exatamente nesses tempos de crise essa narrativa ganha eco e ressoa em todo o País? Essas e outras questões serão escrutinadas no decorrer desta sessão, porém, desde já, adiantamos que, uma hipótese para tal, reside no fato de que valores de convivência, participação, tolerância ou coletividade são incongruentes para o autoritarismo, sendo pois este um momento em que o discurso autoritário predomina e sendo também a escola um espaço em que os valores mencionados acima são constituídos, torna-se possível que esses ataques reflitam o comportamento social do nosso tempo.

A partir dessa reflexão e provocação é que iniciamos esta seção, cujo foco recai sobre a negação da escola enquanto negação de um direito humano fundamental que é a educação. Dentro desta seara buscamos perceber nuances que ora aproxima, ora afasta a escola de posições significativas ao desenvolvimento pleno do sujeito ou a um lugar de doutrinação ideológica da esquerda, respectivamente.

Contudo, a ideia de uma escola instrumentalizada não é nova, a base da educação crítica reside na denúncia de uma escola aparelhada ideologicamente, pensemos em Althusser (1980). Mais radical que o francês, o Russo Ivan Illich (1985) declara uma "Sociedade sem escola". Entretanto a novidade da contemporaneidade recai sobre os atores envolvidos. A crítica histórica de uma educação inclinada aos interesses das classes dominante sempre foi prerrogativa dos setores populares, dos movimentos de resistência, dos sujeitos sociais históricos. Contudo, agora esse ataque advém exatamente dos setores das classes dominantes, dos grandes capitalistas e dos grupos mega conglomerados que empreendem no setor da educação privada.

Mas quando analisamos os sujeitos que engendram essa crítica à escola básica pública, cujo teor é reproduzido nas camadas subalternas - como salienta Gramsci (1988) acerca do conceito de ideologia - percebemos a partir dos próprios sujeitos que todo esse discurso de negação da escola não é desinteressado, pelo contrário, é aí que reside o projeto e os interesses dos grandes empresários do setor da educação privada. Portanto, há que se habituar a refletir profundamente sobre todo e qualquer ataque, do alto ou de baixo, nunca é somente uma opinião, é a construção 
de uma narrativa que se enraíza no seio da sociedade e mais tarde pode se materializar de forma obscura e obscurantista.

Coadunando com a perspectiva crítico reprodutivista, ou seja, a compreensão de que a escola enquanto instituição é forjada a partir dos interesses das classes dominantes, mas indo além, sobretudo a partir de uma compreensão do educador brasileiro Paulo Freire (1983), ou seja, de que a escola também é impactada pela cultura das classes populares e compreendendo ainda que essa mesma escola é uma instituição fundamentalmente necessária à conscientização e aos processos de organização das classes subalternas, temos pois, um diagnóstico e uma pista significativa quanto ao interesse e a negação dessa instituição pelas classes dominantes.

A negação da escola às classes trabalhadoras foi um instrumento largamente utilizado na história do Brasil. A começar pelos negros, esses que indubitavelmente foram os mais negligenciados em se tratando de acesso à educação (MONTEIRO, 2007). Assim é preciso destacar a importância da educação escolar e universitária para os incipientes, porém significativos avanços alcançados pelas classes subalternas durante o período das políticas sócio-educacionais e de distribuição de renda empreendidas, sobretudo, nos governos Luiz Inácio Lula da Silva e Dilma Rousseff.

Esse destaque ao acesso à educação, com ênfase sobretudo nas camadas mais precarizadas da sociedade acabou por desvelar também um aspecto social fortemente presente na sociedade brasileira, mas que por vezes camufla-se numa narrativa de harmonia e "democracia racial", esse aspecto se materializa na incapacidade das classes dominantes conviverem com o diferente e de compartilhar espaços sociais com as classes trabalhadoras.

Essas incongruências sociais que são externadas nesses momentos de crise são fundamentais para a compreensão efetivamente real da sociedade brasileira. Há em nosso país uma presença fortemente marcada pela herança da colonização e da escravidão. Esses dois fenômenos que se complementam no processo de construção da identidade nacional acabam por delegar aos pretos e pardos, aos indígenas, e de modo geral às pessoas pobres, um lugar à margem das riquezas do País.

Essa herança predatória e formativa da sociedade brasileira não deve ser negligenciada sob pena de perder-se da real compreensão dos fenômenos atuais. E quando se trata de educação essa análise torna-se fundamentalmente necessária para entender o desenho histórico sobre o qual a escola erigiu no Brasil.

Como sabemos, a educação destinada às camadas populares esteve quase sempre associada ao utilitarismo, a necessidade de ampliação das massas eleitorais ou ao processo de industrialização 
do Brasil do século XIX (SAVIANI 2013). No século XX, a consolidação da mecanização da lavoura fomentou o ensino técnico para vastas camadas populares, sobretudo para jovens e adultos no período noturno. Ainda nesse período, ensaios de educação libertadora, empreendidas no campo dos movimentos de cultura popular e materializadas no trabalho de Paulo Freire, apresentam um contraponto educacional significativo no cenário brasileiro e coloca a Educação Popular como perspectiva de emancipação e conscientização das camadas trabalhadoras.

A crítica feita por Paulo Freire e por todos os movimentos populares dos anos de 1960, decantam durante o Regime Militar (1964-1985) e voltam à cena política após a derrocada do período ditatorial. Porém, esse discurso emerge a partir de uma narrativa internacional de democratização ventilado sobretudo pela queda do muro de Berlim (1989) e a busca pela garantia dos direitos humanos. Esse cenário de ascensão dos direitos sociais recoloca a educação enquanto um direito fundamental inerente a todos os brasileiros e uma obrigação do Estado na garantia, é o que advoga a nova Constituição Federal do Brasil de 1988.

Nesse contexto, se torna consenso a importância da educação escolar para a formação do cidadão brasileiro. Desse modo, no interstício que compreende 1988 à 2016 a sociedade brasileira conviveu com governos ora mais conservadores, ora mais progressistas, alguns mais inclinados à educação fundamental, outros abrangendo da Educação Básica ao Ensino Superior, porém, todos coadunavam quanto a relevância social da instituição escolar para a formação integral das crianças, jovens e adultos.

Contudo, paulatinamente, uma narrativa diferenciada começa a ganhar corpo na sociedade brasileira. A partir de 2016, um discurso que afirma que a escola é um espaço de doutrinação, denominado pelo que se convencionou chamar nos espaços conservadores de "ideologia de gênero", ganha adeptos. Esses dois fenômenos - doutrinação mais ideologização - logo foram acolhidos na linguagem dos grupos políticos de extrema direita. Não tardou e isso materializou-se em Projeto de Lei (PL 246/19 - Escola Sem Partido). Por outro lado, as organizações de classe, sindicatos e associações de docentes, reagiram ao que chamaram "Lei da mordaça" defendendo a liberdade de cátedra escrito na Constituição e na Lei de Diretrizes e Bases da Educação Nacional (LDB 9.394/96). (BRASIL, 1996).

O fato é que, a partir dessa conjectura, pela primeira vez, tanto os professores quanto às instituições escolares foram colocados à margem social, inclusive na narrativa, fato esse inédito na história de um país que, pelo menos em retórica, sempre elegeu a educação como de importância fulcral ao desenvolvimento social, político e econômico da nação. 
Estabelecido o dissenso e espraiando-se ideias de que escolas são espaços de formação de militantes de esquerda e que professores são doutrinadores marxistas e ainda que têm o poder de determinar a preferência sexual dos alunos, tudo isso ecoando a partir de falas tanto do ministro de estado da Educação, quanto do próprio presidente da república, acarreta em sérias consequências para todos aqueles envolvidos de alguma forma com a educação brasileira, em última análise ganha força, por exemplo ensino doméstico, o chamado bomeschooling.

Feito este breve ensaio, reiteramos aquilo que já explicitamos no início desta seção, ou seja, a negação da escola é parte inerente à negação dos direitos sociais mais gerais é também a degradação de valores fundamentais que sempre nortearam a sociedade brasileira, é a crise da legalidade, é muito mais que a educação em crise, é a tentativa da criação de uma educação para crise, uma educação pautada pelo moralismo e pela disciplina militarista, reconhecidamente fracassada em diversas partes do mundo e incongruentes com o nosso tempo histórico, com a necessidade criativa do cidadão desse tempo, com uma educação integral, pautada na perspectiva dos direitos humanos. É sobre essa temática que nos deteremos a partir de agora.

\section{Como a educação em direitos humanos pode responder a crise na educação}

Pode a Educação em Direitos Humanos responder às graves questões relacionadas a negação da educação e da escola, levantadas na seção anterior? Pode ela contribuir com a formação de uma narrativa que recoloque a escola no centro dos processos de humanização? Acreditamos que a Educação em Direitos Humanos tem um corpus de conhecimentos e experiências acumuladas ao longo de algumas décadas que podem contribuir de forma significativa com a escola e com os processos de desenvolvimento humano e social.

A Educação em Direitos Humanos é uma perspectiva educativa que está contida dentro da seara dos Direitos Humanos. No Brasil e na América Latina essa perspectiva é recente, data da segunda metade da década de 1980, quando a união entre movimentos sociais populares e a luta contra regimes ditatoriais se combinam enquanto prática educativa (CANDAU, 2013).

No Brasil, o marco legal conhecido como Plano Nacional de Educação em Direitos Humanos, lançado em 2003, busca alinhar o papel social da educação à temática da cultura dos Direitos Humanos. "O PNEDH está respaldado em documentos internacionais, notadamente no Programa Mundial de Educação em Direitos Humanos (PMDH) e no seu plano de ação" (CADERNO DE EDUCAÇÃO EM DIREITOS HUMANOS, 2013, p. 9).

Para além do marco legal, a Educação em Direitos Humanos é uma ferramenta teóricoprática de importância significativa para amalgamar os processos educativos à necessidade de 
formação integral que a contemporaneidade enseja. Ela é um caminho de acesso aos demais direitos sociais. Tem sido uma esperança em meio aos exemplos rotineiros de transgressão e violação dos direitos. Por isso, acreditamos que a Educação em Direitos Humanos reafirma valores e princípios fundamentais à convivência, tais como a pluralidade, a solidariedade e a coletividade. Além disso, o fortalecimento dessa perspectiva na escola representar um aspecto relevante e um sinônimo de resistência.

$\mathrm{Na}$ contramão de uma educação para a crise, ou seja, intencionalmente direcionada a responder às demandas de uma sociedade da intolerância, a educação em direitos humanos tem por finalidade uma educação para a mudança e transformação social pautada nos seguintes princípios:

I- dignidade humana; II- igualdade de direitos; III- reconhecimento e valorização das diferenças e das diversidades; IV-laicidade do Estado; V- democracia na educação; VItransversalidade, vivência e globalidade; e VII- Sustentabilidade socioambiental (BRASIL, 2012).

Desse modo, compreendemos que uma escola que considera tais princípios no sentido de garanti-los em sua integralidade, mas também que educa para o exercício desses, comunga com uma educação em/para os direitos humanos. É de extrema importância que a escola assuma tal protagonismo com possibilidade de enfrentamento as posturas anti-democráticas, arbitrárias e autoritárias que permeiam a atualidade. O combate as violações de Direitos Fundamentais é um dos caminhos para a convivência, a paz e a construção de um novo paradigma de vida em sociedade.

Como traçar um percurso formativo nas instituições escolares que comunguem com ações direcionadas a prática de uma Educação em Direitos Humanos? Magdenzo (2005 apud Candau et al., 2013) destaca alguns princípios que devem nortear essas práticas, tais como:

1. Princípio de recorrência: Concernente a constância que deve se consolidar a através da temática dos Direitos Humanos na escola. Possibilitando a apresentação através de diferentes formas para que seja possível vivenciá-la e interiorizá-la;

2. Princípio da vida cotidiana: Analisar situações do cotidiano relativas aos direitos humanos, tanto nas violações quanto na afirmação da garantia;

3. Princípio da integração: $O$ tema relativo aos Direitos Humanos deve integrar áreas curriculares do projeto político-pedagógico das escolas;

4. Princípio da coerência: Consolidar a relação teoria e prática na escola para que diálogos e atitudes possam comungar com a prática em educação em direitos humanos; 
5. Princípio da apropriação: Alunos e professores trabalhando a temática ativamente, a partir de suas existências e promovendo interiorização e atribuição de sentido;

6. Princípio de construção coletiva do conhecimento: Os educadores são convidados a estimular uma atitude ativa dos alunos e alunas através de debates, diálogos e outras formas de participação.

Esse conjunto de princípios deve, sobretudo, considerar a realidade desses estudantes. É importante, ainda, ressaltar que, com a atualização dos Projetos Político- Pedagógico das escolas em acordo com a nova Base Nacional Comum Curricular (BNCC) e, tendo os Direitos Humanos entre as competências específicas, a discussão se solidifica enquanto exequível e urgente na atualidade.

Dar respostas através da educação em direitos humanos a uma crise que, sobretudo, fundamenta uma sociedade reprodutora de desigualdade, intolerância e autoritarismo além de ousado revela a importância desse paradigma enquanto promotor de mudanças. Educar em/para os direitos humanos produz empoderamento e reconhecimento das pessoas enquanto sujeitos de direitos e, isso, requer acesso à informação, mas também exercício da cidadania. "Ser sujeito de direito supõe também desenvolver a consciência do poder que cada pessoa tem e isso passa pela visão de uma cidadania ativa e participativa como um componente fundamental da construção democrática." (CANDAU et al.,2013, p.43).

Portanto, os caminhos traçados para uma educação em direitos humanos na escola perpassam por ações de participação, exercício da cidadania, criticidade, democracia, combate às intolerâncias em todas as suas facetas e, sobretudo, garantia de direitos humanos. Formar professores e estudantes nessa perspectiva reafirma um compromisso permanente com a humanização dos sujeitos. Resposta profícua no combate a crise da sociedade atual.

\section{Considerações finais}

Desde o início desses escritos perguntávamos se vale a pena insistir na perspectiva dos Direitos Humanos em tempos de crise, ainda mais quando pensamos que essa crise pode ter caráter permanente. Caminhando agora sobre essas considerações finais entendemos que não basta somente afirmar que sim, mas que vale a pena reafirmar esse sim a partir das nossas ações concretas junto aos sujeitos da educação, junto às escolas e na formação dos professores e professoras que efetivamente constroem o processo de ensino e aprendizagem.

Vale a pena disputar cada palmo do espaço educativo, vale a pena disputar cada segundo da narrativa educativa com aqueles que estão comprometidos com a ingerência da formação 
humana, estão comprometidos com a barbárie, advogando ser esse o caminho natural da humanidade. Com isso, a educação em direitos humanos tem uma tarefa muito evidente: defender o óbvio! Defender que a caminhada da humanidade não tem fim na barbárie, mas pelo contrário, a caminhada humana é humanizante e tem finalidade na humanização.

Não é possível, nem cabível que a escola e toda a sua luta histórica para se tornar melhor, comungue, ainda que minimamente, com uma narrativa rasa, solucionista e pragmatista. Nenhum militarismo, nenhuma censura irão resolver do dia para a noite problemas cristalizados e enraizados na própria condição da escola. Não existe soluções mágicas para a complexidade da educação do nosso tempo, nem de nenhum outro. Há esforços, trabalho individual e coletivo que podem apresentar boas saídas para os muitos problemas do campo educacional.

Assim é que compactuamos com todo um arcabouço teórico que advoga a relevância da educação em direitos humanos para o fortalecimento da educação, das relações interpessoais e sobretudo do desenvolvimento de outras formas de convivência cuja base desloque o eixo da competição desmedida à cooperação e ajuda mútua. Isso tudo pode parecer estranho ao nosso tempo. Se sim, é que já estamos atrasados nesta caminhada, uma vez que tais valores jamais devem nos parecer estranhos.

$\mathrm{Na}$ escola, entendemos que a Educação em Direitos Humanos deve atuar como uma ferramenta transversal que deve perpassar o currículo, o planejamento a aula e também a gestão, a formação de professores e professoras e todos os demais processos e relações que caracterizam a escola. Finalmente destacamos mais uma vez o tempo de crise no qual a educação em direitos humanos se inscreve, por isso mesmo é tão urgente sua defesa, sua experimentação, afinal, o tempo de crise é isso, pode nos atrasar e retroceder aos mais longínquos e primitivos períodos da nossa história, mas também pode representar um tempo para a reinvenção do tradicional, pode representar a criação do novo, o "inédito viável" como afirma Freire (1983). Nesse texto, esperançamos essa segunda opção.

\section{Referências}

ALTHUSSER, Louis. Ideologia e aparelhos ideológicos de Estado. 3. ed. Lisboa: Editorial Presença/Martins Fontes, 1980.

BALL, Stephen; MAINARDES, Jefferson. (Org). Politicas Educacionais: questões e dilemas. São Paulo: Cortez, 2011.

BAUMAN, Zygmunt. BORDONI, Carlo. Estado de Crise. Trad. Renato Aguiar. 1. ed. Rio de Janeiro: Zahar, 2016. 
SILVA, Linda Carter Souza da; SILVA FILHO, Luiz Gomes da. Educação em direitos humanos em tempos de crise

BOBBIO, Norberto. Liberalismo e democracia. 6. ed. São Paulo: Brasiliense, 2005.102p.

BOGDAN, Robert; BIKLEN, Sari. - Características da investigação qualitativa. In: Investigação qualitativa em educação: uma introdução à teoria e aos métodos. Porto, Porto Editora, 1994. p.47- 51.

BRASIL. Programa Mundial para Educação em Direitos Humanos. ONU. Brasília, 2012. Disponível em: https://unesdoc.unesco.org/ark:/48223/pf0000217350_por. Acesso em: 28 Out. 2019.

BRASIL. MEC. Diretrizes Nacionais para a Educação em Direitos Humanos. Resolução Nº1 de 30 de Maio de 2012. Disponível em:

http:/ / portal.mec.gov.br/index.php?option=com_docman\&view=download\&alias=10889rcp001-12\&category_slug=maio-2012-pdf\&Itemid=30192. Acesso em: 22 Mai. de 2017.

BRASIL. Ministério da Educação. Secretaria da Educação Básica. Base nacional comum curricular. Brasília, DF, 2018. Disponível em: http://basenacionalcomum.mec.gov.br/\#/site/inicio. Acesso em: Out. 2019.

BRASIL. Lei 9.394 de 20 de dezembro de 1996. Brasília, Secretaria de Assuntos Jurídicos da Casa Civil. Disponível em: http://www.planalto.gov.br/ccivil_03/leis/L9394.htm . Acesso em: 03 fev. 2020.

BRASIL. Caderno de educação em direitos humanos. Educação em Direitos Humanos: Diretrizes Nacionais, Brasília, 2013.

CANDAU, Vera Maria. Et al. Educação em Direitos Humanos e formação de professores(as). 1 ed. São Paulo: Cortez, 2013.

COMPARATO, Fábio Konder. A Afirmação Histórica dos Direitos Humanos. São Paulo: Editora Saraiva, 2010.

FREIRE, Paulo. Educação como prática da liberdade. 14 ed. Rio de Janeiro: Paz e Terra, 1983.

FREIRE, Paulo.. Pedagogia do Oprimido. Rio de Janeiro: Paz e Terra, 2011.

GAZIER, Bernard. A Crise de 1929. Porto Alegre: L\&PM Editores, 2009.

GIL, Antônio Carlos. Métodos e técnicas de pesquisa social. São Paulo: Atlas, 1999.

GIL, Antônio Carlos.Métodos e técnicas de pesquisa social. São Paulo: Atlas, 2008.

GIL, A. D.; BARIZÃO, D. F. A crise econômico-financeira de 2008/2009 e seu impacto no Brasil. Revista Horizonte Científico. 6(1), 2012.

GOFFMAN, Erving. Estigma: notas sobre a manipulação da identidade deteriorada. Rio de Janeiro: Editora Guanabara Koogan S.A, 1988.

GRAMSCI, Antonio. Os intelectuais e a organização da cultura. 6 ed. Trad. Carlos Nelson Coutinho. Rio de Janeiro: Editora Civilização Brasileira, 1988. 
HOBSBAWN, Eric. Era dos extremos: o breve século XX:1914-1991. Trad. Marcos Santarrita. São Paulo: Companhia das letras, 1995.

ILLICH, Ivan. Sociedade sem escola. trad. Lúcia Mathilde Endlich orth. 7.ed. Petrópolis - RJ. Vozes, 1986.

MAGDENZO, Abraham. Educación em Derechos Humanos. Bogotá: Cooperativa Editorial Magisterio, 2005. IN: CANDAU, Vera Maria; PAULO, Iliana; ANDRADE, Marcelo; LUCINDA, Maria da Consolação; SACAVINO, Susana; AMORIM, Viviane. Educação em Direitos Humanos e formação de professores(as). 1. ed. São Paulo: Cortez, 2013.

MICHAELIS. Dicionário da Lingua Portuguesa. Disponível: http:/ / michaelis.uol.com.br/modernoportugues/busca/portugues-brasileiro/crise/. Acesso em: 29 Out. 2019.

MONTEIRO, Denise Mattos. Introdução à bistória do Rio Grande do Norte. 3. ed. Natal: RN: EDUFRN, 2007.

SAVIANI, Demerval. História das Ideias Pedagógicas no Brasil. São Paulo: Autores Associados, 2013.

TOURAINE, Alain. Após a crise: a decomposição da vida social e o surgimento de atores não sociais. Trad. Fracisco Morás. Petrópolis, RJ: Vozes, 2011.

Recebido em: 18 mar. 2020/ Aprovado em: 31 jul. 2020

Cite como

(ABNT NBR 6023:2018)

SILVA, Linda Carter Souza da; SILVA FILHO, Luiz Gomes da. Educação em direitos humanos em tempos de crise. Dialogia, São Paulo, n. 36, p. 470-483, set./dez. 2020. Disponível em: https://doi.org/10.5585/dialogia.n36.16827.

\section{American Psychological Association (APA)}

SILVA, L. C. S. da., \& SILVA FILHO, L. G. da. (2020, set./dez.). Educação em direitos humanos em tempos de crise. Dialogia, São Paulo, 36, p. 470-483.

https://doi.org/10.5585/dialogia.n36.16827. 